\title{
Facial nerve injury. A short review
}

\author{
JoHN M. POTTER \\ D.M., F.R.C.S. \\ Department of Neurological Surgery and Accident Service, \\ The Radcliffe Infirmary, Oxford
}

\begin{abstract}
Summary
Despite considerable advances in technique, experience and skill, the precise place of surgery in the treatment of facial nerve injury remains uncertain. The mechanism of delayed facial palsy is not yet clear, and there is still debate about the value of tests for early evidence of denervation. Recent literature has been reviewed.
\end{abstract}

\section{Introduction}

In recent years, there has been a large volume of literature relating to disorders of the seventh cranial nerve. Understandably, idiopathic facial paralysis (Bell's palsy) has received more attention than the traumatic lesions though, as regards diagnostic methods and treatment, the two groups have much in common. The intention here is to outline only the complex problem of the injured nerve and to do this briefly, for the subject has been treated more extensively elsewhere (Potter and Braakman, 1976).

It needs to be emphasized that the literature is abundant in claims and assertions, and that there is debate about the mechanism of delayed traumatic paralysis, as there is about that of Bell's palsy. The practical value of various tests for facial denervation is both believed and doubted; and there is much consequent disagreement about the precise place of surgical exploration of the injured nerve.

With these considerations in mind readers are referred, for their own critical assessment, particularly to the selected papers from the 2nd International Symposium on Facial Nerve Surgery published in volume 95 of the Archives of Otolaryngology (1972). It should be noted that the title of the symposium implies a bias towards surgery, and that it had been claimed elsewhere that 'Otolaryngologists are the keepers of the facial nerve' (Graves and Tabb, 1971).

\section{Forms of injury}

The facial nerve may be injured in the course of surgery or as part of an accidental head injury. At surgery, it may be damaged in the cerebellopontine angle, at various operations on the temporal bone, during the extradural approach for retrogas-

Correspondence: Mr J. M. Potter, Department of Neurological Surgery, The Radcliffe Infirmary, Oxford OX2 6HE. serian trigeminal neurectomy, and in the course of removal of parotid-gland tumours. In head injuries, branches may be directly contused or lacerated in the face, or the nerve itself involved in its bony (fallopian) canal by a fracture (usually longitudinal) of the petrous bone.

The paralysis associated with petrous fractures is usually recognized as being either immediate, when the nerve is directly lacerated or contused at the site of the fracture, or delayed in its appearance for a period of from 1 to 14 days, usually 2-3 days (Potter, 1964).

The mechanism of delayed paralysis is not clear, but it seems likely that one or more of the following factors are responsible. The nerve may be compressed by its own increasing swelling within its unyielding fibrous sheath or epineurium (Jongkees, 1972). This swelling may be a delayed response to trauma to the nerve itself, or secondary to damage to its surrounding vasculature resulting in delayed arterial spasm or arterial or venous thrombosis. There may also be external compression of the nerve by expanding haematoma fluid (Turner, 1944), or by oedema of the loose fibrous tissue and periosteum between the nerve itself and the bony wall of its canal (Hazama et al., 1972).

A third or mixed group of cases may also be seen (Potter, 1964), where some degree of immediate weakness is noticed which may even show some recovery before the delayed process sets in and, after an interval, causes a worsening or even a completion of the paralysis.

In recorded series of delayed facial palsy the prognosis has been good.

\section{Incidence}

In Turner's (1944) seventy war-time cases of facial palsy complicating closed head injury, the incidence was $5 \%$. But in civilian hospitals, where many patients with mild concussion are admitted for a night or two, the proportion is understandably less. In a personal series of 2712 consecutive and unselected cases of head injury, the author (Potter, 1964) found an incidence of almost exactly $1 \%$. Of the twentyseven patients, twenty-four were male and only three female. Their ages ranged from 4 to 61 years 
(average 29), and there was no relationship between the incidence or severity of the facial palsy and the length of the post-traumatic amnesia.

\section{Associated clinical features}

Apart from those injuries occurring distal to the stylomastoid foramen, it is seldom that a traumatic facial palsy occurs without either a demonstrable fracture of the temporal bone, or a bleeding ear (or haemotympanum) on the affected side. Usually there are both, and occasionally there is also cerebrospinal fluid otorrhoea. Indeed, in the series just referred to, patients with some degree of facial paralysis accounted for approximately $50 \%$ of all those showing fractures of the temporal bone.

\section{Diagnostic tests}

The bedside diagnosis of facial weakness is usually clear, although the recognition of minor degrees requires a practised eye and attention to such features as incomplete blinking and the extent to which the eye-lashes can be buried by active movement.

\section{Localization}

If surgical exploration of the nerve is contemplated, it is helpful if the site of injury can be ascertained beforehand. Fracture lines may be demonstrated by appropriate radiography (Hughes, in Rowbotham, 1964), and the testing of such functions as those subserved by the chorda tympani (taste on the anterior two-thirds of the tongue), the nerve to the stapedius (stapedial reflex), and by the greater superficial petrosal nerve (tear production) will indicate lesions proximal or distal to the points at which these nerves enter or leave the fallopian canal. For a general review of these tests, readers are referred to the paper of Langerholm, Moritz and Toremalm (1971), and for the use of electrogustometry to that of Tomita et al. (1972).

\section{Denervation and prognosis}

In recent years there has been much refinement of electrodiagnostic methods for detecting denervation; yet, as has been said, these constitute a debatable subject. The practical need is for a reliable means of predicting denervation but, as May et al. (1971) admit, while expressing their preference for the maximal stimulation test, 'an ideal test for peripheral facial paralysis has not been found'. Yanagihara and Kishimoto (1972) review current methods.

\section{Treatment}

Prophylaxis

If the incidence of traumatic facial palsy is to diminish it is necessary to continue to urge both the use of sufficient head protection for those exposed to head injury, and an adequate training to provide the necessary skill required for those who will carry out surgical procedures on the temporal bone and parotid gland.

Corticotrophin may be administered for 8 days from the day of injury to patients showing both a bleeding ear and radiological evidence of an ipsilateral temporal fracture. This has been shown to reduce the incidence of delayed facial weakness from an expected $38 \%$ to one of only $8 \%$ (Briggs and Potter, 1967, 1971). The prognosis for this form of palsy is, however, generally so good that the justification is not great for the routine use of such a prophylactic measure, which is not entirely innocuous.

\section{Expectant treatment}

The basis for the attitude of those who favour a wait-and-see policy (they are mostly neurologists and neurosurgeons) is that, in the vast majority of all cases of traumatic facial palsy, there is spontaneous recovery (Turner, 1944; Rowbotham, 1964; Potter, 1964). Such recovery is often complete, but even if incomplete, the degree of recovery is usually sufficient to be acceptable to the patient and his relatives, and it is often equal to that obtained with surgical assistance. The questions are: what is acceptable, and to whom? And, would surgery have given a better result, and how does one know this?

If, following months of expectant (conservative) management, a complete facial paralysis is clearly permanent, all is not lost; for improvement may still be achieved either by an operation that will restore some nerve conduction or by skilled plastic surgical procedures.

While awaiting recovery from a complete palsy, the flaccid cheek may be supported by various devices, of which elastic plaster is probably the most satisfactory. Interrupted galvanic stimulation is commonly recommended, but its value is doubtful. Where eye closure is defective, the patient should be urged to seek advice at the first sign of any conjunctival inflammation. The serious complication of 'neuroparalytic keratitis' is more likely to occur if there is associated defective lacrimation, and even more if there is also loss of corneal sensation. Against this complication a precautionary lateral canthorrhaphy is advisable; but if the condition threatens to become established, expert ophthalmological attention will be required.

\section{Surgery to the nerve}

As has been indicated already, the status of surgical treatment in traumatic, as in Bell's, facial palsy remains unsettled. Its proponents have mostly been otologists (e.g. Cawthorne and Haynes, 1956; Kettel, 1959; Jongkees, 1972), and technical advances 
have been considerable in the 50 years since Ballance and Duel (1932) started this work. These two pioneers believed that 'the moment to operate is now'-which may be so; but when is 'now'? Ideally, this should be before the onset of denervation, i.e. prophylactically; but mention has already been made of the limitations of such tests as are available to help the surgeon to decide when the right moment has arrived.

Whether the procedure is to be decompression of the nerve, neurolysis, end-to-end anastomosis or nerve grafting, all operations on the temporal bone require a high degree of modern technical expertise from specialists in this field if bad results are not to obscure successes. The surgical anatomy of the fallopian canal has been well described by, for example, Anson et al. (1970). There is less doubt about who should do these operations than about whether and when they need to be done. It cannot be denied that good results follow appropriate operations in well selected cases, or that the operations themselves appear to have been responsible. Equally-but as in so many clinical situationsconvincing statistical proof from a well controlled clinical trial is lacking.

Following operations on the cerebellopontine angle, a purposely sacrificed facial nerve may be grafted in the way described by Drake (1972) as an alternative to the more usually performed faciohypoglossal anastomosis.

\section{Plastic surgery}

There is something to be said for an operation which will restore a completely paralysed half-face at least to a position of symmetry while at rest. Such an achievement calls for skill which is no less specialized than that required for surgical exporation of the fallopian canal. The resulting tranquillity of expression, even if somewhat 'wooden' during much of facial movement, may nevertheless contrast favourably with the sometimes wildly inco-ordinated grimaces seen in those cases where, although facial nerve conduction has been successfully re-established to a considerable degree, this has probably been through different and inappropriate Schwann sheaths, or as a result of axonal branching. Reference should be made to the works of plastic surgeons: for example, Peet and Patterson (1963) describe a method which has given satisfactory results in their hands; and Edgerton (1967) draws attention to certain points of surgical technique which, he considers, improve the prospect of achieving the best possible result. Good results from these operations are not, however, always lasting, and revision procedures may be required.

\section{Conclusions}

It may be suggested that something fundamental is usually overlooked in the pursuit of any thera peutic approach which aims to re-establish conduction in the facial nerve after denervation has occurred. Restoration merely of muscular movement and power unilaterally is not enough when it is the synchronous co-ordination of emotional expression on the two sides of the face that is all-important. Any comparison with the satisfactory suture of, say, a divided ulnar nerve is of only partial validity; for in the hand, muscular power and facility are the important components, whereas-at any rate in the average Englishman's hand-the ability to convey emotional expression is dispensable (Potter, 1964).

\section{References}

Anson, B.J., Warpeha, R.L., Donaldson, J.A. \& ReNsINK, M.J. (1970) The facial nerve, sheath and blood supply in relation to the surgery of decompression. Annals of Otology, Rhinology and Laryngology, 79, 710.

Ballance, C. \& Duel, A.B. (1932) The operative treatment of facial palsy. Archives of Otolaryngology, 15, 1.

Briggs, M. \& PotTer, J.M. (1967) Prevention of delayed traumatic facial palsy. British Medical Journal, 4, 464.

Briggs, M. \& PotTer, J.M. (1971) Prevention of delayed traumatic facial palsy. British Medical Journal, 3, 458.

CaWthorne, T. \& Haynes, D.R. (1956) Facial palsy. British Medical Journal, 2, 1197.

DRAKE, C.G. (1972) Facial function after intracranial repair of facial nerve. Archives of Otolaryngology, 95, 420.

EDGERTON, M.T. (1967) Surgical correction of facial paralysis; a plea for better reconstruction. Annals of Surgery, 165, 985.

Graves, T.A. \& TABB, H.G. (1971) Management of traumatic facial nerve paralysis. Laryngoscope, 81, 645.

Hazama, H., Tamaki, H., Nomura, A., Furukawa, Y. \& Uetsuka, H. (1972) Compression of the facial nerve. Archives of Otolaryngology 95, 346.

JONGKEES, L.B.W. (1972) On peripheral facial nerve paralysis. Archives of Otolaryngology, 95, 317.

KeTtEL, K. (1959) Management of peripheral facial palsy due to trauma. Proceedings of the Royal Society of Medicine, 52, 1069.

Langerholm, S., Moritz, U. \& Toremalm, N.G. (1971) Peripheral facial palsy. Functional diagnosis. Acta otolaryngologica, 71, 329.

May, M., Harvey, J.E., Marovitz, W.F. \& Stroud, M. (1971) The prognostic accuracy of the maximal stimulation test compared with that of the nerve excitability test in Bell's palsy. Laryngoscope, 81, 931.

Peet, E.W. \& PATterson, T.J.S. (1963) The Essentials of Plastic Surgery, pp. 212-221. Blackwell Scientific Publications, Oxford.

PotTER, J.M. (1964) Facial palsy following head injury. Journal of Larynogology and Otolaryngology, 78, 654.

Potter, J.M. \& BraAkman, R. (1976) Injury to the facial nerve. In: Handbook of Clinical Neurology (Ed. by P. J. Vinken and G. W. Bruyn), vol. 24, p. 105. North-Holland Publishing Co., Amsterdam.

Rowbotham, G.F. (1964) Acute injuries of the Head, 4th edn, pp. 424-427. E. and S. Livingstone, Edinburgh and London.

Tomita, J., OKuda, Y., TomiYama, H. \& Kida, A. (1972) Electrogustometry in facial palsy. Archives of Otolaryngo$\log y, 95,383$.

TURNER, J.W.A. (1944) Facial palsy in closed head injuries. Lancet, i, 756.

YANAGIHARA, N. \& Kishimoto, M. (1972) Electrodiagnosis in facial palsy. Archives of Otolaryngology, 95, 376. 